\title{
Multilingualism in the Teaching of Gender Studies
}

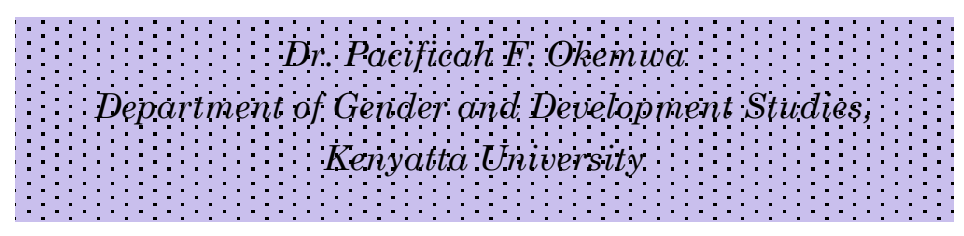

Abstract

How does one introduce the concept "gender" to a first year class? What aspects of their socio-cultural context may one embrace to demonstrate the 'everyday' commonplace reality that gender alludes to? In what ways may students be involved in crafting the meaning of gender using their lived experiences? This paper will explore the use of African culture, more specifically; language, beliefs and practices associated with the social construction of gender. It is noted that much of the scholarship on the understanding of gender concepts are based on Western culture and experience. Yet, in Africa, culture as communicated through language is the overriding determinant of the lives of women, men, boys and girls. It is argued that within local cultural and social settings, the social construction of gender continues and that there are many actors. I n order to achieve vision 2030, and specifically the social pillar, gender equality must be one of the values communicated and taught in the school. In this regard, the paper will endeavour to demonstrate how this 
may be done. A procedure that incorporates and critiques African culture will be explored. It is anticipated that this will provide clues to social transformation and therefore, a way of working towards achieving gender equality.

Key Words: Multilingualism, gender, African culture proverbs, folktales.

\section{Introduction}

Much of the scholarship on the understanding of gender concepts are based on Western culture and experience as gender studies as an academic discipline is a relatively new area of study in many institutions of higher learning in Africa. In Kenya, efforts to introduce gender/feminist/ women studies date back to the late 1990s (Okemwa, 2007). However, due male domination in the management of institutions of higher learning, gender/ feminist/ women studies was incorporated in the curriculum in mid 2000. Available publications in this nascent period were mainly from the West as they have engaged these discourses since the $19^{\text {th }}$ century (cf. Levine $\&$ Hole, 1979). It is however worth noting that, African culture still remains the overriding of women and men's lives in various linguistic and ethnic communities represented in Africa. 
Within the local cultural and social settings gender is constructed and communicated through language hence the emphasis on gender as reality that continues to be constructed, reconstructed and even deconstructed over space and time.

This paper focuses on the use of multilingualism in teaching introductory courses in Gender. The aim of this course $\mathrm{s}$ is to define key concepts and relate these to contemporary experiences and realities. Methods of delivery of the course content are highly participatory. Therefore, students take part in question and answer sessions and role plays among other activities which generate ideas that make up components of the definitions. This makes the definitions and their usage part and parcel of everyday thinking of the students. This however, presents serious challenges because many African cultures are patriarchal in orientation hence societal norms and customs often favour men over women in terms of resource allocation, rights and voice (cf. World Bank, 2001). Careful interrogation of African cultural practices however, reveals high levels of egalitarianism. In this regard, Snyder \& Tadesse (1997) argue that "although it cannot be said that all women had equality with men - a balance of economic responsibility did prevail between 
men and women...". In their view therefore, both women and men participated in some functions of overall government and women at times reached positions of high authority (Ibid, 76). Consequently gender inequalities may be attributed to colonization, neo- colonialism and their attendant forces that changed the gender division of labour as well as relations between women and men in many African communities. In view of the above, it is noted that the social construction of gender continues and that there are many actors and socialization agents including the family, community, media, religion, school; all of which are influenced by existing sociocultural realities.

In this paper, it is argued that in order to achieve vision 2030, and specifically the social pillar, gender equality and equity must be one of the values communicated and taught in the school. In this regard, I will endeavor to demonstrate how this may be actualized. My view is that multilingualism may be used to not only enrich the content of Gender Studies but also the appreciation of the meaning of gender as a reality that informs all aspects of human life in specified socio-cultural contexts. 
The first part explores ways of defining gender using multilingualism. It is noted that African languages are rich and students whose formative years were in a traditional/ rural setting provide critical detail with regard to the social construction of gender that differs from the explications by those who are brought up in an urban setting. It is worth noting that this knowledge is not based on the past (what used to be) but on the present (what is).

Thus, it is noted that African culture is a living reality that is dynamic, and that changes are part and parcel of the reality. Culture is an ever changing reality often responding to global developments in education, technology, scientific innovations among other advancements. The second part discusses how men and women are made. Here the centrality of language as central in transmission of beliefs and practices and shaping societal explications on men and women is emphasized. The third part explores creative ways of incorporating multilingualism into our education system. It is argued that this will enrich the content, pedagogy and therefore, the acquisition of new knowledge. 


\section{Definitions}

\section{African Reality and Culture}

I do not speak for all cultures in Africa. The students in the undergraduate program originate from various communities in Kenya therefore, I refer to these. Their lifestyles are diverse pastoralists, agriculturalists, rural, urban among others are represented. The peoples of Africa in general and Kenya in particular are adherents of various religions including Islam, Christianity and African religions among others. The common defining principle for all African peoples is the influence of African culture on our lives. In this paper I use Taylor's' definition of culture as, "The complex whole which includes knowledge, beliefs, art, morals, customary laws, regulations and any other capabilities and habits acquired by human beings as members of specific societies" (1871).

Each ethnic community has a distinct language of communication. Languages are carriers of the values, beliefs and practices of peoples. Language, thus, communicates peoples' experience and it is also intimately involved in the construction and organization of that experience. Oduol (1993: 
39), therefore, notes, "when the ideology, the body of ideas characteristic of a particular society or subculture has a gender bias, the language of that society will be equally biased." Therefore, as a child learns a language s/he also acquires the cultural understanding of who s/he is and what is expected of them as gendered beings.

\section{Gender}

There are many definitions available. However, many of these allude to the fact that gender refers to the social definition of women men, boys and girls. Baker (2006) defines it as the attributes, roles, and activities connected to being a man or a woman. That is, how women and men are perceived, and how they are expected to behave in a given culture, time and place. The definition implies that many of the differences between men and women are socially and culturally constructed and may change over time. These differences are reflected in gender roles, responsibilities, access to resources, opportunities and perceptions of women and men. Gender therefore considers women and

men and their interdependent relationships (Moser, 1993; Lorber, 2000). 


\section{Multilingualism in Education}

This refers to the existence and use of several languages in teaching and learning.

\section{Methodology}

This paper is based on lecture room experiences over a period of about five years. The number of students enrolled varied from year to year. However, it is noted that the figures have been on the rise ranging from twenty-six in the 2007/2008 academic year to three hundred and eighty in the 2011/2012 academic year. At least more than thirteen ethnic communities representing distinct languages are often represented including the Agikuyu, Kalenjin, Kamba, Luhya, Luo, Aembu, Ameru, Abagusii, Somali, Maasai, Samburu, Turkana, Mijikenda and the Taita. The first exercise undertaken is to identify the terms for 'woman' and 'man' in local languages and to explain the meaning attached to the identified terms in their communities. The aim of this exercise is to create awareness of who we are as men and women; and to emphasize the basis of these self definitions.

Two concepts - gender and language inform the explications in this paper. There is therefore, a 
need for a theoretical framework that explains the two and shows how they relate. As noted earlier, gender is a social construct. Therefore, the society into which one is born and brought up equips both boys and girls with the knowledge and skills they need in order to be men and women who fit those definitions as per societal expectations, roles and responsibilities. In view of this, Nasong'o and Ayot (2007:166) note that cultural socialization experiences transmitted through parents, schools, peers, and the media are key in shaping the images of women and men. In this process, language is invaluable as it is through language that social reality and societal expectations are transmitted. Yieke (2004) therefore opines that language is a powerful tool for looking at, creating and recreating reality in different ways as well as communicating such reality.

It is however, important to move beyond surface level examination of discourses to the deep structures that inform such descriptions particularly in gender studies. Critical discourse studies see organizations not simply as social collectives where shared meaning is produced, but rather as sites of struggle where subtle relations of power and inequality are enacted and displayed. Fairclough (1992) 
notes that power is already accruing in some participants and not others and that this power is determined by their place and roles in the community, socio-economic status, gender and ethnic identity. Thus, social relations of power pre-exist the talk itself. With regard to African communities, it would generally be argued that men already posses power, it is part of their reality by virtue of their gender. Women on the other hand are often socialized into a secondary position in relation to men and through gender role socialization and stereotypical expectations; they have internalized such inferior position (cf. Walker 1990). There are however, differences among women due to their differing socio-cultural contexts and the differing variable factors that may in turn inform the gender discourse in such contexts. These include class, race, religious affiliation and ethnic background among other variables.

\section{Why Multilingualism in the Teaching of Gender?}

In this section, reference is made to lecture room experiences in the last five years. This essentially implies these may not be generalized. I however, need to underline that if Gender scholars in Africa are to produce independent knowledge on 
the subject, then publication of experience however localized will be mandatory. Oduyoye (1995:5) notes that this may be one of the ways of shedding off the Western garb that gender and women studies in Africa have been dressed in. In addition, this is one way of demonstrating that gender scholars in Africa are not necessarily aping "Western culture thereby discarding African values..." (Ahikire 2004:56). Hence, I argue; there is need to incorporate African gender discourse in the teaching of gender. This has to be done in ways that enhance the dignity of Africans as well as ensure both equity and equality between men and women.

A number of advantages of multilingualism have been noted. First African languages clearly demonstrate the nuances of gender. For example, in explaining the place of society in the construction of gender, I often refer to the meaning of the words used for man and woman in local languages. Among the Agikuyu for instance, there are many terms that mean "man". Some of these are, Muthuri, Mundurume and Njamba. On the other hand, the terms that may be translated to "woman" include Mutumia and Mundu Muka among others. Each of these terms has very specific meanings among the Agikuyu hence my observation that 
these terms underline, differences, attitudes and perceptions regarding men and women. In addition the different terms imply that there are several understandings of what it means to be a man or a woman among African communities as is the case among the Agikuyu. The single terms - man and woman hardly communicate the differing understanding but the African languages do.

Second, multilingualism allows for the use of oral literature from a wide range of African communities in the lecture room. This affords the class an opportunity for a critical examination of the social reality that has been transmitted from one generation to another. What emerges is that African languages provide codes for interpretation of traditions, values and cultural realities. Perhaps this explains why many scholars of Gender and Women studies in various fields have used aspects of local languages in their writing (cf. Oduyoye, 1995; Shisanya, 1996:186-194; Okemwa, 1996:177-185). Gender scholars from the West have also noted the significance of deep rooted familiarity with local customs and practices as communicated in African languages when teaching Gender related courses in Africa (Stewart, 2011). 
The various forms of oral literature are of interest to gender scholars as these explain how ideologies are formed and sustained. In teaching, students are guided to search for proverbs, songs, folktales and myths from various communities, more so their own and in mother tongue. These are then translated into English and discussed in light of the theme or topic under discussion. What often emerges is the depth of the language used and that the translation often waters down the meaning of these oral forms of literature. Perhaps the work of Oduyoye who studied the Yoruba of Nigeria and the Akan of Ghana is informative. She interrogates myths, folktales and proverbs of the two communities from an African woman's perspective. Below are some excerpts from the publication.

...proverbs are weighty and couched in formalized language as they are, they easily acquire the status of potent speech; once spoken, they become authoritative statements with a life of their own. ...each proverb has more than one level of meaning; when they are used in the right context, people sit up and listen, regarding them as a legal precedent (1995: 19f).

And on folktales she had this to say: "Folktales may be ingeniously constructed and entertaining, when effectively told, however, they do 
become an authoritative source for describing how life is and prescribing what ought to be" (ibid: 20).

It is however noted that in order to guard against the gender inequalities communicated in oral literature, the language used requires thorough interrogation and application in the light of contemporary social context and realities. Such language determines the images and attitudes as well as thoughts about women and men. While it is not possible to reproduce these, I note that the language used often portrays women and men as different but united and in need of each other. Thus some portray women negatively or positively; bring out the weaknesses of men or even communicate gender roles in specific communities (cf. Oduyoye, 1995; Wanjohi, 2001).

Third, multilingualism helps identify ideologies that have often been used by various communities to subjugate women while elevating the status of men. My view is that, for equality between men and women is to be realized; we as a society must travel back in time to unearth the basis of inequalities, interrogate them, and then communicate life giving ideologies crafted out of existing realities and the gender equality agenda. My experience is 
that we may not be successful in this agenda until we seriously consider the ideologies regarding women and men as communicated through the various African languages. For instance, in one of the classes, a young man from among the Samburu could not find words in English that could express in detail the significance of circumcision. He therefore, acted these out and chanted in mother tongue selected aspects of the circumcision ritual. This drama was then interpreted with the help of another student and lecturer from among the Samburu. From this the whole class noted how male the circumcision ritual accords status among the initiates as individuals and learned the cultural meaning of some of the non verbal communication. The following for me were new lessons on male circumcision:

- That the leaders of age-sets are identified during the rituals surrounding initiation. This was done through counting the number of a certain type of bird that the initiate had been able to kill. The initiates made a head gear out of this which was won during the integration dance, where they entered the village in a single file led by the person whose head gear had most birds and the last being one with the least or none. 
- That initiation earned the young men sexual rights over young initiated but unmarried girls. These girls were attached to specific warriors (morans) by being beaded. Thus warriors had to work very hard in order to afford the beads. This in most cases meant taking part in cattle rustling from neighbouring communities and exchanging these for money or the desired beads.

The permanence of the lessons learned during the presentation was worthwhile. The reason for such permanence was essentially the interplay between drama, language as well as all the verbal and non verbal communication not to mention the young man's love and appreciation of his culture. These however, had to be carefully interrogated for meaning, impact on gender relations, gender equity and equality, the human rights of the young people, sexual health, education and environmental concerns. In my view, therefore, the use of multilingualism in teaching is the key to unlocking cultural knowledge and encouraging critical discourses that may have a positive impact in transforming gender relations among peoples in their socio-cultural contexts. How this may be done is dealt with in the next section. 


\section{Methodological Approach in Teaching Gender in an African Context}

In this section I focus on how the experiences presented in this paper may be organized into a more standardized procedure that may be applied at various levels of education. The use of multilingualism is emphasized due to the significance of language. The procedure involves four steps including; reflecting on experience, analyzing social reality, Relating social reality to existing theories and clues to transformation. These are explained and thereafter, presented in a figure.

\section{Step 1. Reflecting on Experience}

In this first step it is noted that students' experiences of culture or their social reality is the starting point when thinking about gender issues. This involves engaging students in simple tasks (discussions, role plays, drama) based on day-to-day life experiences which can only be accomplished in reference to their cultures or social contexts. The selection of tasks is aligned to the topic under investigation. 


\section{Step 2. Analyzing Social Reality}

This step involves analyzing social and cultural reality in order to highlight meaning and implications of the experiences. Students are therefore, encouraged not to take anything for granted including the words, actions and drama that accompany the experiences they describe. For instance, the word njamba in Gikuyu language is used in reference to a man, and the same people have a proverb that says "njamba ti ya mwera umwe" (a cock does not service / belong to one hen). A good student will easily make the connection between men's sexual behavior and that of cocks. The language here communicates behavior that is associated with men. In addition sexual relations with many partners is also justifiable as being part of men's nature in some African cultures. Therefore, developing a hermeneutics of suspicion implies not just accepting what is communicated, even when it is presented as a people's culture, cultural knowledge or moral teaching. Thus, step two involves questioning what is communicated as social reality.

Step 3. Relating to Existing Theories

This involves referring to existing theories that explain the experiences related by students in 
first step. For instance, the theories that explain gender relations in society are explored. In addition policies, legal frameworks that critique African culture as well as unequal regard of women and men are explored. The aim of this kind of reading is to explore channels of social transformation and renewal. This is done by ensuring that the search for explanatory theories yields life-affirming ways of being and relating. Thus, answers are generated as to why social constructs that downplay women's dignity and humanity have to resisted. In light of this, I emphasize that, student-centered learning has the power to change their ways of thinking and application of socio-cultural norms in their lives.

\section{Step 4. Clues to Transformation}

As noted in the diagram below, this step involves finding new ways of acting that may lead to transformation. At this point, the discussion often turns to identifying what could be done to transform gender relations in society based on the new knowledge gained. This includes identification of new ways of relating and structures that need to be put in place in order to ensure that women and men, girls and boys are able to enjoy their human rights and access justice. 


\section{Procedure in Use of culture/Multilingualism in Teaching Gender}

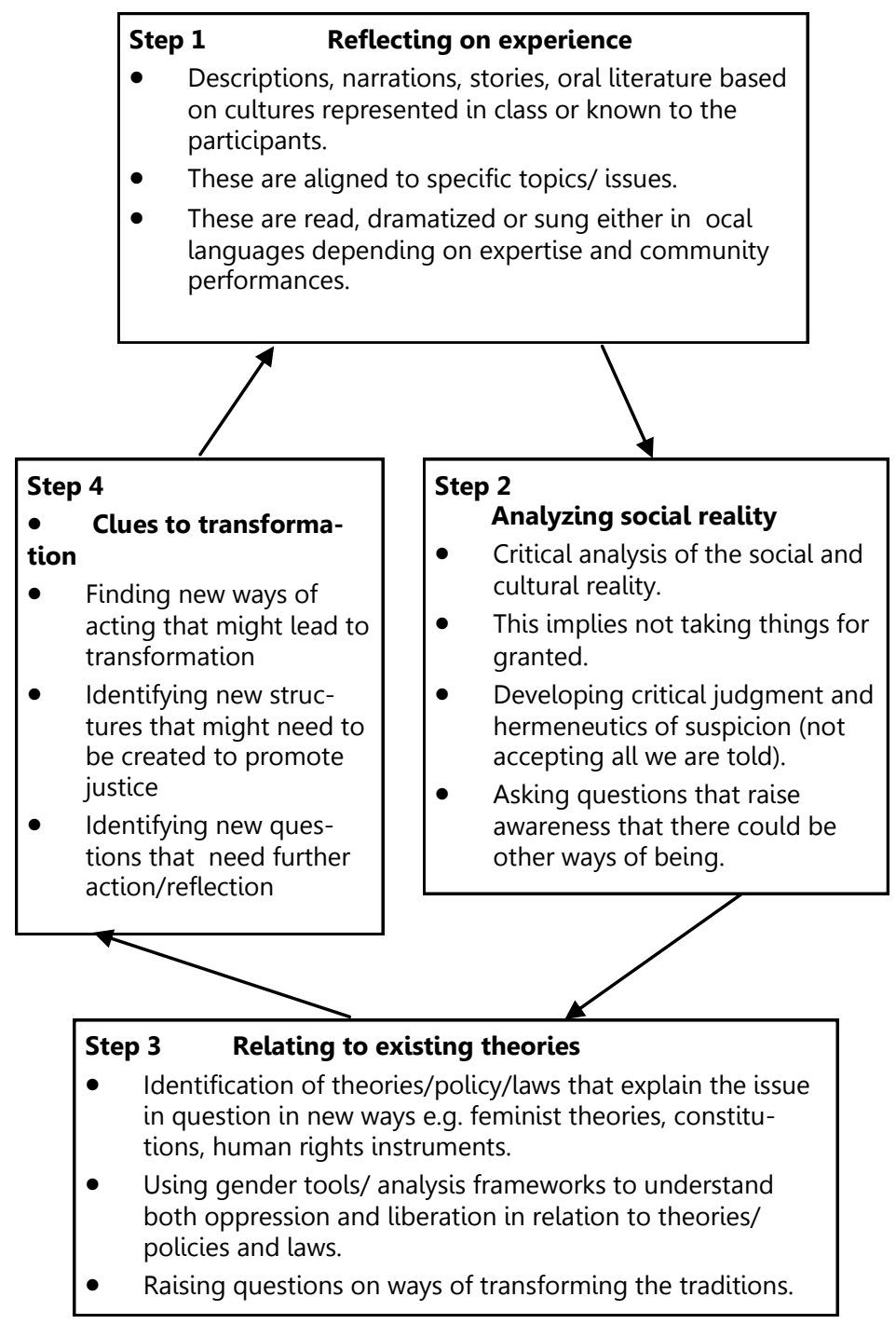




\section{Conclusion}

This paper has underlined the significance of multilingualism in gender studies in an African context. The role of African languages in explaining meaning in the gender discourse is noted. How this may be done in a classroom situation is explained. I however note the flexibility often afforded by use of lived experiences in teaching and learning. I therefore submit, this approach underscores the variability of gender in the African context. The use of multiple languages in pedagogy, however, requires an approach that accommodates, respects all and enables critical consideration of each in its own right. 


\section{References}

Ayisi E.O. (1972). An introduction to the study of African culture. Nairobi: East African Publishers.

Ahikire, J. (2004). "Locating Gender Studies in the Pan African Ideal: A Reflection on Progress \& Possibilities in Uganda." In Arnfred S., Chacha, B.K., Gouws, A., Ahikire, J., Ogundipe A., Pereira, C., Prah M., Ukeje C., \& Yieke, F.A. (2004), Gender activism and studies in Africa. Dakar: CODESRIA

Kabira, W. M. (1993). "Gender and Ideology: The Cultural Context.” In Kabira, W. M., Oduol, J. A. \& Nzomo, M. (eds.) Democratic change in Africa. Women's perspective. Nairobi: AWORD.

Levine, E., \& Hole, J. (1979). "The First Feminisms". In Freeman J. O. (ed.). Women: A Feminist Perspective ( $3^{\text {rd }}$ ed.) California: Mayfield Publishing Company.

Lorber, J. (2000). "The Social Construction of Gender" In Ore, T.E (ed.). The social Construction of Difference and Inquality. Race, class, gender and sexuality. Mountain View, California: Mayfield Publishing Company.

Moser, C. (1993). Gender planning and development:

Theory, practice and training. London: Routledge. 
Nasong'o, S. W., \& Ayot, T. O (2007). "Women in Kenya's Politics of Transition and Democratization" In Murunga, G.R \& Nasong'o, S.W. (eds.). Kenya. The struggle for Democracy. Dakar: CODESRIA.

Ndungo, C. M. (2006). "The Images of Women in African Oral Literature" In Gender Issues

Research Report Series No. 23 Addis Ababa, Ethiopia: OSSEREA.

Oduyoye, M. A. (1995). Daughters of Anowa. New York: Orbis Books.

Oduol, J. A. (1993). "Gender and Ideology: The Role of Language” In Kabira W. M, Oduol, J. A . \& Nzomo, M. (eds.). Democratic change in Africa women's perspective. Narobi: AAWORD.

Okemwa, P. F (2007). An Assessment of Responses towards African Women's Theology in Selected Institutions in Kenya. $\mathrm{PhD}$ Thesis, Kenyatta University.

Okemwa, P. F. (1996). "Clitoridectomy Rituals and the Social well - being of Women" In Kanyoro, M. R. A. \& Njoroge, N. J. (eds.). Groaning in faith. African women in the house hold of God. Nairobi: Action Publishers.

Okemwa, P. F. (1993). "The Place and Role of Women in the Seventh Day Adventists Church.” M.A. Thesis, Kenyatta University. 
Shisanya, C. R. A. (1996). "Death Rituals" In Kanyoro, M. R. A. \& Njoroge, N. J. (eds.). Groaning in faith. African women in the house hold God. Nairobi: Action Publishers.

Wanjohi, G. J. (2001). Under one roof. Gikuyu proverbs consolidated. Nairobi: Paulines Publishers Africa.

World Bank. (2001). Engendering development through gender equality rights, resources and voice. New York: Oxford University Press.

Yieke, F. A. (2004). "Collaborations or Warriors? A Sociolinguistic Analysis of the Discourse Patterns of Men and Women in their Claim for Space in Public/Formal Workplace.” In Arnfred S., Chacha, B.K., Gouws, A., Ahikire, J., Ogundipe, A., Pereira, C., Prah, M., Ukeje, C., \& Yieke, F. A. (2004). Gender activism and studies in Africa. Dakar: CODESRIA. 